\title{
Dynamic Simulation of Low-Carbon Competitiveness from the Perspective of Circular Economy
}

\author{
Xing Li $(\mathbb{D}$ and Fuzhou Luo \\ School of Management, Xi'an University of Architecture and Technology, Xi'an 710055, China \\ Correspondence should be addressed to Xing Li; shinelixing@hotmail.com
}

Received 11 December 2020; Accepted 19 June 2021; Published 29 June 2021

Academic Editor: Atila Bueno

Copyright ( 92021 Xing Li and Fuzhou Luo. This is an open access article distributed under the Creative Commons Attribution License, which permits unrestricted use, distribution, and reproduction in any medium, provided the original work is properly cited.

\begin{abstract}
In accordance with the requirements of the circular economy in Guangxi (of PRC) and the characteristics of the drivers of lowcarbon competitiveness in the regional construction industry, a causal flowchart of influencing factors of the low-carbon competitiveness in the Guangxi construction industry is constructed, and a model based on system dynamics is established. After the entropy weight method is used to determine the variable weight, VENSIM PLE software is used to simulate the development trend of the low-carbon competitiveness of the Guangxi construction industry. The simulation results of the promotion effect of various factors on the development of the low-carbon competitiveness of the regional construction industry from 2010 to 2020 are obtained, and countermeasures and suggestions are proposed from the perspective of a circular economy.
\end{abstract}

\section{Introduction}

With the development of the economy and the change in urbanization, the demand for construction in China is increasing. With the change in science and technology and the transformation of industry, the construction industry should adhere to green development and make the low-carbon industry goal to realize the transformation, upgrading, and circular development of the construction industry.

The report of the 18th National Congress emphasized that China must "adhere to the basic national policy of saving resources and protecting the environment, adhere to the principle of giving priority to saving, protecting, and restoring nature, and strive to promote green development, circular development, and low-carbon development, to form a spatial pattern, industrial structure, mode of production, and lifestyle for saving resources and protecting the environment, to reverse the deterioration trend of the ecological environment from the source, and to create a good production and living environment for the people" (The 18th National Congress of China, 2020) [1].

In the "Opinions on Promoting the Sustainable and Healthy Development of the Construction Industry" issued by the General Office of the State Council in 2017, the construction industry is the pillar industry of the national economy but remains "big but not strong." In the overall requirements, the document was proposed to "firmly establish and implement the development concept of innovation, coordination, greenness, openness, and sharing" and emphasized the importance of promoting the modernization of the construction industry. Energy-saving, emission reduction, and transformation to green development were also mentioned [2].

Over approximately the past decade, governments at all levels in China have attached substantial importance to the development of a circular economy and strictly implemented it in accordance with relevant policies and legal documents proposed by various national ministries and commissions. The Guangxi Zhuang Autonomous Region has a unique ecological environment and tourism resources and actively develops the circular economy while fully integrating the regional ethnic characteristics and reality. The region's "Twelfth Five-Year Plan" Research Report on the Development of the Guangxi Circular Economy and the "Guangxi Circular Economy Development" Thirteenth Five-Year Plan "Research 
Report" and other related research reports have obtained valuable results [3].

As one of the pillar industries of Guangxi's economy, the construction and related industries have always been at a relatively low level in terms of technology and development in the country's horizontal comparison. They are in the status quo of high energy consumption, high pollution, and low output, which is the means for Guangxi to achieve sustainable development and a circular economy. As one of the key industries, it is necessary and forward-looking to explore the low-carbon competitiveness and optimization path of the Guangxi construction industry from the perspective of a circular economy.

Some scholars combined the relevant background and cases of the "Research Report on the 12th Five-Year Plan for the Development of Circular Economy in Guangxi," summarized the implementation effect of the development of a circular economy in Guangxi, and proposed guarantee measures [4-6]. Fang used the theories of circular economy, industrial ecology, and regional development combined with the methods of grey correlation analysis and AHP and discussed the influencing factors of the development of the low-carbon economy in the Guangxi Beibu Gulf Economic Zone and the countermeasures to improve the development level [7]. Grant used Porter's competition theory as the basis to explore the influencing factors of the competitiveness of the construction industry [8]. Momaya and Selby used Porter's diamond model to analyze the influencing factors of the competitiveness of the construction industry in Canada and make a comparison with Japan and the United States [9]. Based on Porter's diamond model, Betts and Ofori innovatively proposed that policy organization and arrangement, government influence, and cultural factors should also be included in the analysis model of construction industry competitiveness [10]. Li and Jiang analyzed the dynamic development of the low-carbon construction industry in Jiangsu Province through the decomposition method of LMDI and found the decoupling effect between it and economic growth [11]; Dong et al. have also found the decoupling situation in five northwest provinces of China [12]. Li et al. have conducted surveys in Central Asia [13]; Zhao et al. started from the transportation industry, analyzed the drivers of carbon emission in the transportation industry in Guangdong from 1995 to 2012, and found that the positive impact of policies is particularly important [14]; Jiang discussed the project management and low-carbon management of construction products from the microperspective to realize the sustainable development of construction products [15].

Jiahong and Wenbin summarized the low-carbon development status of the four aforementioned central provinces and proposed corresponding countermeasures through the factor analysis method by combining the relevant statistical data of Hubei, Hunan, Henan, and Anhui provinces from 2000 to 2011 [16]. Qingfeng uses Malmquist's index decomposition method based on DEA, combines the carbon emission performance of 29 provinces in China into the framework of all-factor analysis, and evaluates the change rule of carbon emission performance in the eastern, central, and western regions of China [17]. Fei and Dajian conducted theoretical research on domestic and foreign low-carbon cities, combined with model indicators to evaluate and analyze carbon emissions in the process of urban development, and proposed development strategies for a low-carbon cycle of urban life and material production [18]. Juchun et al. have conducted a multifaceted factor analysis on the low-carbon competitiveness of the construction industry and evaluated its low-carbon competitiveness by using structural equation models and other methods [19-21]. Ying and Hui discussed the energy-saving benefits of low-carbon development and transformation in the construction industry from the perspective of economic analysis [22]. Qinghua et al. have reviewed and summarized the research on low carbon in the construction industry by means of Atlas analysis and proposed the establishment of policies such as a carbon tax and a carbon emission trading mechanism based on the advanced experiences in China and other countries [23].

In previous studies on the relationship between energy consumption and economy, some scholars adopted econometric methods to analyze the impact of macroeconomic indicators, such as population [24], gross domestic product (GDP) [25-29], industrial structure [30], urbanization rate [31], and energy structure [32, 33]. These studies could better explain the causal relationship between macroeconomic indicators and energy consumption. However, few scholars considered the impact of the whole energy supply chain process.

Most research on the low-carbon competitiveness has been in the theoretical analysis stage and has not conducted empirical analysis on the combination with regional characteristics [34-36]. For the core areas of China's coastal, riverside, and border development, Guangxi, which uses the phrase "mountain green and water clean" as its motto, has the characteristics of a strong dependence on resources and a fragile ecological environment [37]. Therefore, it is imperative to analyze and evaluate the competitiveness of the regional construction industry, explore the internal dynamics and laws of the low-carbon transformation and sustainable development of the construction industry, provide decision-making information for local governments and enterprises, and offer a reference for other regional construction industries managing the same bottleneck.

\section{Material and Methods}

2.1. Energy Consumption Level of Construction Industry in China. Since the 1980s, China's economy has achieved leapfrog development, in which the role of the construction industry in promoting economic development cannot be ignored. However, with the rapid economic development, we should focus on the increasingly serious "ecological deficit" problem, especially high energy consumption and high carbon emissions of the construction industry [38-40]. Therefore, it is urgent to seek the direction and path of lowcarbon industrial transformation by analyzing the energy consumption of China's construction industry. For the calculation of carbon emission from the construction 
industry, the main reference is the calculation method in the IPCC report published in 2006 [41]. The calculation formula is as follows:

$$
\sum_{i=1}^{m} \text { Resource }_{i} \times \alpha_{i}+\sum_{j=1}^{n} \text { Energy }_{j} \times \beta_{j} .
$$

From Tables 1 and 2 and Figure 1, it is found that the carbon emission level in eastern China is significantly higher than that in central and western China, and it increased significantly in 2011 and 2012, and then the growth trend slowed down. However, the overall carbon emissions are increasing year by year, and there is a certain degree of synchronization with the economic development in different regions of China. At the same time as China's economic development, the current situation of carbon emissions from the construction industry should also be taken into consideration. It is particularly necessary for the construction industry to carry out a low-carbon transformation, industrial upgrading of the construction industry, and circular economy.

2.2. Causal Analysis of Factors Influencing the Low-Carbon Competitiveness of the Guangxi Construction Industry Based on System Dynamics. According to the current economic development status of Guangxi and the current production characteristics of the construction field, combined with Guangxi's overall plan for the development of a circular economy during the "Thirteenth Five-Year Plan" period, and in accordance with the method of system dynamics to determine the system boundaries and key variables, the key factors were extracted from many documents. These factors include low-carbon industrial structure, regional economic environment, low-carbon levels of related industries, and low-carbon industrial demand, of which the low-carbon industrial structure is the internal cause, and the regional economic environment, low-carbon level of related industries, and low-carbon industrial demand are the external causes. Due to the needs of the regional economic environment, the demand for low-carbon industries is driven, which promotes the low carbonization of related industries and the low-carbon competitiveness of the construction industry; the low-carbon industrial structure affects direct and indirect carbon emissions throughout the construction process, responds to the low-carbon competitiveness of the construction industry, and builds a cycle of internal and external factors. According to the subdivision observation variables of each factor, the following factor subdivision structure diagram was obtained (Figure 2).

In accordance with the influence of the relationship between the internal and external factors and the formation process of motivation, we obtained a causal flowchart of the low-carbon competitiveness of the Guangxi construction industry (Figure 3).

\subsection{Guangxi Construction Industry Low-Carbon Competi-} tiveness Model Based on System Dynamics. According to the causal flow of Guangxi's construction industry's low-carbon competitiveness in Figure 2, we must determine various variables and observation indicators before establishing a system dynamics model.

Variable 1: low-carbon competitiveness of the Guangxi construction industry (GXJZ)

Variable 2: demand for low-carbon products in the construction industry (JZCP), including fixed asset investment and real estate investment

Variable 3: regional economic environment (GXJJ), observed through GRP (gross regional products)

Variable 4: low-carbon degree of relevant industries (XGCY), observed by industrial carbon emission efficiency and energy carbon emission efficiency

To ensure the unity of our numerical calculations, the original absolute value is nondimensionalized in the data processing process, and the rate is calculated on the same base.

Based on the aforementioned variables and observation indexes, combined with the characteristics of the Guangxi construction industry, the system dynamics equation is established as follows:

(1) Guangxi regional economic environment evaluation equation: according to the characteristics of China's current economic development and urban construction, the GDP in economically developed regions is relatively high, and the corresponding construction demand is relatively high. China's construction level, technical level, and management level tend to lead, which is a positive impact on the low-carbon competitiveness of the construction industry. When the level of low-carbon competitiveness of the regional construction industry increases, it will also promote the optimization of the regional economic environment. In view of research, local protectionism often hinders benign competition, affects the optimization of motivation, and has a negative effect on regional economic growth. Combined with the system dynamics equation model, the feedback equation for the regional economic environment in Guangxi is defined as follows [42-44]:

$\mathrm{GXJJ}=[1+f(\mathrm{GXJZ})] \times \mathrm{GRP} \times f\left[2-\left(S_{1}\right)^{a}\right]$

where GXJJ is the Guangxi regional economic environment, GRP are the gross regional products, $f(y)$ is the smoothing function, and $S_{1}$ is the coefficient of local protection degree.

According to Juchun et al. [42], a coefficient of the local protection degree $1 \leq S_{1} \leq 2$ of 1 indicates that the region is completely open and there is no local protectionism; a coefficient of 2 indicates that the region is completely closed and there is completely local protectionism. Based on Guangxi's regional characteristics and development background, the 
TABle 1: Energy consumption data of construction industry in China (coal equivalent calculation) (10,000 tons).

\begin{tabular}{|c|c|c|c|c|c|c|c|c|c|c|c|c|c|}
\hline Year & 2005 & 2006 & 2007 & 2008 & 2009 & 2010 & 2011 & 2012 & 2013 & 2014 & 2015 & 2016 & 2017 \\
\hline Beijing & 47.9 & 48.1 & 50.8 & 55.3 & 65.7 & 77.0 & 82.2 & 84.6 & 76.9 & 73.2 & 75.8 & 77.0 & 73.6 \\
\hline Tianjin & 50.4 & 59.9 & 71.3 & 140.0 & 157.3 & 182.0 & 200.3 & 210.5 & 214.4 & 217.7 & 230.9 & 237.24 & 228.04 \\
\hline Hebei & 96.7 & 225 & 232.4 & 253.6 & 274.7 & 310.1 & 339.6 & 352.3 & 209.8 & 202.9 & 297 & 312 & 315 \\
\hline Shanxi & 80.8 & 89.8 & 93.4 & 108.0 & 130.6 & 145.5 & 158.0 & 166.4 & 178.2 & 161.1 & 163.08 & 163.28 & 166.08 \\
\hline Inner Mongolia & 97.1 & 110.3 & 116.3 & 150.2 & 177.5 & 299.6 & 246.0 & 254.1 & 240.1 & 236.9 & 302.36 & 367.70 & 428.33 \\
\hline Liaoning & 101.0 & 109.6 & 130.8 & 141.8 & 160.1 & 187.0 & 209.8 & 194.9 & 202.5 & 163.4 & 171.6 & 158.37 & 136.7 \\
\hline Jilin & 86.9 & 98.3 & 102.8 & 62.5 & 70.0 & 83.5 & 90.1 & 98.2 & 144.2 & 142.9 & 125.32 & 126.18 & 128.55 \\
\hline Heilongjiang & 14.3 & 15.4 & 15.4 & 16.6 & 20.9 & 30.0 & 42.6 & 47.4 & 52.1 & 54.3 & 55.0 & 56.9 & 55.4 \\
\hline Shanghai & 173.8 & 180.2 & 180.7 & 191.9 & 204.5 & 200.9 & 189.5 & 205.7 & 207.4 & 200.2 & 217.70 & 236.6 & 240.9 \\
\hline Jiangsu & 208.4 & 224.5 & 236.2 & 242.0 & 259.6 & 172.0 & 193.8 & 201.9 & 238.2 & 252.4 & 377.84 & 349.66 & 357.57 \\
\hline Zhejiang & 196.5 & 215.3 & 234.9 & 256.1 & 288.2 & 348.7 & 378.0 & 383.3 & 432.1 & 446.2 & 450.6 & 466.3 & 478.4 \\
\hline Anhui & 57.1 & 66.3 & 74.4 & 88.5 & 95.0 & 116.6 & 139.7 & 159.5 & 196.7 & 205.6 & 209.47 & 220.69 & 241.21 \\
\hline Fujian & 54.2 & 69.2 & 76.1 & 137.8 & 146.3 & 166.7 & 188.3 & 176.3 & 191.7 & 198.6 & 246.22 & 258.6 & 270.5 \\
\hline Jiangxi & 16.9 & 142.4 & 129.9 & 125.4 & 152.8 & 37.9 & 51.7 & 54.2 & 70.2 & 78.3 & 109.2 & 114.34 & 122.71 \\
\hline Shandong & 594.4 & 588.9 & 594.9 & 603.5 & 715.4 & 275.3 & 309.6 & 286.6 & 277.5 & 292.4 & 453.3 & 472.1 & 486.6 \\
\hline Henan & 65.4 & 68.0 & 69.0 & 70.1 & 92.4 & 126.7 & 157.3 & 161.4 & 170.3 & 203.4 & 269.7 & 263.44 & 323.86 \\
\hline Hubei & 134.2 & 162.1 & 183.4 & 183.1 & 227.6 & 298.9 & 331.8 & 326.5 & 360.5 & 374.7 & 428 & 367 & 379 \\
\hline Hunan & 122.8 & 125.1 & 133.2 & 111.4 & 135.1 & 162.3 & 201.9 & 222.1 & 266.7 & 297.8 & 360.64 & 377.91 & 380.04 \\
\hline Guangdong & 182.3 & 196.5 & 222.9 & 228.5 & 236.7 & 255.7 & 266.9 & 275.5 & 272.2 & 303.6 & 734.13 & 740.18 & 767.84 \\
\hline Guangxi & 33.6 & 44.4 & 43.1 & 31.0 & 36.0 & 37.9 & 45.0 & 46.2 & 48.3 & 53.5 & 59.90 & 62.06 & 69 \\
\hline Hainan & 11.6 & 12.8 & 14.2 & 13.9 & 18.4 & 23.9 & 28.3 & 32.7 & 38.1 & 46.2 & 48.12 & 47.8 & 52.80 \\
\hline Chongqing & 59.1 & 67.6 & 75.3 & 94.3 & 91.5 & 111.3 & 131.3 & 135.4 & 151.4 & 159.8 & 166.3 & 180.2 & 192.1 \\
\hline Sichuan & 121.6 & 128.1 & 182.7 & 158.3 & 190.8 & 241.7 & 278.1 & 254.1 & 216.4 & 216.6 & 498.1 & 548.5 & 579.3 \\
\hline Guizhou & 48.5 & 47.5 & 41.5 & 60.8 & 73.2 & 79.4 & 73.0 & 84.4 & 115.0 & 140.7 & 129.3 & 161.07 & 184.25 \\
\hline Yunnan & 75.2 & 87.3 & 91.2 & 115.8 & 128.2 & 153.7 & 183.0 & 184.0 & 181.4 & 198.2 & 215.13 & 232.01 & 255.84 \\
\hline Shaanxi & 66.3 & 92.1 & 62.1 & 144.1 & 117.4 & 160.8 & 163.7 & 178.5 & 184.0 & 200.2 & 205.80 & 192.27 & 209.51 \\
\hline Gansu & 57.8 & 58.8 & 61.0 & 63.8 & 65.4 & 78.5 & 88.4 & 96.5 & 98.3 & 109.1 & 103.67 & 110.68 & 121.47 \\
\hline Qinghai & 14.8 & 16.6 & 16.5 & 22.9 & 24.8 & 28.5 & 33.9 & 36.8 & 40.2 & 41.8 & 46.5 & 45.6 & 51.3 \\
\hline Ningxia & 13.6 & 15.4 & 18.3 & 33.4 & 39.4 & 47.6 & 50.3 & 53.8 & 56.6 & 58.5 & 60.6 & 65.8 & 67.2 \\
\hline Xinjiang & 39.8 & 50.2 & 50.6 & 54.5 & 64.2 & 70.0 & 84.5 & 101.2 & 117.5 & 108.4 & 155.6 & 202.4 & 207.6 \\
\hline
\end{tabular}

value of $S_{1}$ here is 1.5 , which indicates that the degree of local protection is semiopen.

Formula (3) is substituted into the numerical value as follows:

$\mathrm{GXJJ}=[1+f(\mathrm{GXJZ})] \times \mathrm{GRP} \times f\left[2-(1.5)^{a}\right]$.

Formula (3) shows that the economic environment of Guangxi takes the GDP of Guangxi as an indicator, which is positively affected by the low-carbon competitiveness of Guangxi and negatively affected by local protectionism.

(2) Demand evaluation equation of low-carbon products in the construction industry: the low-carbon products in the construction field are mainly reflected in the real estate industry and fixed asset investments from the industrial chain terminal, which are affected by the policy guidance in the aforementioned commodity market. Guangxi belongs to the autonomous region of ethnic minorities. Thus, on the one hand, Guangxi is subject to the macrocontrol of the state, and on the other hand, it has certain regional characteristics. Thus, the three factors, respectively, establish the evaluation equation as follows:

$$
\mathrm{GDZC}=\mathrm{GXJJ} \times X_{1},
$$

where GDZC is the fixed assets investment in Guangxi and $X_{1}$ is the coefficient of influence.

$$
\mathrm{FDC}=\mathrm{GXJJ} \times X_{2},
$$

where FDC is the real estate investment in Guangxi and $X_{2}$ is the coefficient of influence.

$$
\mathrm{JZCP}=\left[\mathrm{GDZC} \times \omega_{1}+\mathrm{FDC} \times \omega_{2}\right] \times \lambda,
$$

where JZCP is the demand for low carbon in construction products, $\omega_{1}$ and $\omega_{2}$ are the weight coefficients obtained by the entropy weight method, and $\omega_{1}+\omega_{2}=1, \lambda$ is the policy impact coefficient, according to Guangxi's regional characteristics and development background, and the value of $\lambda$ here is 0.5 , indicating that the region is equally affected by the market and policies.

(3) Industry and energy are the upstream industries of the construction industry, which have a linkage effect with the low carbon of the construction industry; thus, we obtain the evaluation equation for the degree of industrial low carbonization and energy low carbonization. 
TABle 2: Carbon emissions of construction industry in China (10,000 tons).

\begin{tabular}{|c|c|c|c|c|c|c|c|c|c|c|c|c|c|}
\hline Year & 2005 & 2006 & 2007 & 2008 & 2009 & 2010 & 2011 & 2012 & 2013 & 2014 & 2015 & 2016 & 2017 \\
\hline Beijing & 3,489 & 2,574 & 2,746 & 3,237 & 4,544 & 4,722 & 5,633 & 4,923 & 5,448 & 5,771 & 6,492 & 7,303 & 8,216 \\
\hline Tianjin & 863 & 1,108 &, 570 & & 2,310 & 2,352 & 2,898 & 3,322 & & 11,707 & 12,936 & & 15,795 \\
\hline Hebei & 3,530 & 5,302 & 572 & 3,887 & & 10,531 & 31,301 & & 14,602 & 14,577 & & & 19,935 \\
\hline Shanxi & 2,431 & 1,624 & 1,845 & 2,524 & 3,317 & 3,772 & 3,173 & 3,335 & 3,528 & 4,442 & & 5,542 & 6,191 \\
\hline Inner Mongolia & 742 & 901 & 1,182 & 2,684 & 1,696 & 2,280 & 2,331 & 1,922 & 1,940 & 1,926 & 2,123 & 2,339 & 2,578 \\
\hline Liaoning & 2,267 & 2,471 & 2,797 & 3,787 & 8,162 & 7,128 & 11,797 & 11,034 & 13,006 & 12,911 & 14,280 & 15,794 & 17,468 \\
\hline Jilin & 872 & & & & & & & & & & & & 13,606 \\
\hline Heilongjiang & 832 & & & & & & & & & 1,940 & & 2,455 & 2,762 \\
\hline Shanghai & 2,840 & 2,834 & 3,005 & 3,335 & 3,678 & 3,901 & 4,119 & 4,194 & 4,323 & 4,540 & 5,107 & 5,746 & 6,464 \\
\hline Jiangsu & 7,295 & 8,729 & 10,818 & 13,080 & 14,286 & 16,414 & 55,651 & 37,166 & 24,935 & 27,301 & 30,714 & 34,553 & 38,872 \\
\hline Zhejiang & 10,526 & 12,405 & 13,250 & 15,944 & 17,517 & 20,702 & 25,9 & 28,703 & 32,904 & 33 , & & & 47,347 \\
\hline & 621 & & & & & & & & & & & & \\
\hline & 385 & 757 & 2,397 & & 4,672 & 6,213 & & & 11,072 & & & & 19,504 \\
\hline & 1,127 & 1,577 & 1,519 & 1,789 & 2,095 & 2,114 & 40 & 3,772 & 4,321 & 2,191 & 2,450 & & 3,101 \\
\hline Shandong & 4,613 & 5,119 & 4,634 & 8,953 & 8,708 & 9,164 & 9,447 & 27,031 & 10,541 & 11,188 & 12,586 & 14,160 & 15,930 \\
\hline & & & & & & & & & & & & & \\
\hline Hubei & 2,904 & 3,525 & 9,390 & & 7,121 & & 10,3 & 16,728 & & & & & 27,657 \\
\hline & 2,661 & & 3,722 & & & & & & & & & 9,444 & 10,624 \\
\hline Guar & 4,092 & & & & & & & 12,296 & & & & 11,974 & 13,471 \\
\hline Gual & & & & & & & & & & & & & \\
\hline & & & & & & & & & & & & & 662 \\
\hline Chongqing & 1,451 & 1,505 & 1005 & & 3,518 & 5,158 & 5,982 & 5,273 & 6,056 & 6,075 & 6,834 & 7,688 & 8,649 \\
\hline Sichuan & 2,428 & 2,772 & 3,185 & 3,801 & 4,886 & 7,563 & 12,140 & 15,213 & 16,983 & 19,315 & 21,440 & 23,798 & 26,416 \\
\hline Guizhou & 513 & 632 & & & & & & & & & & & 4,639 \\
\hline & & & & & & & & & 11,884 & 12,335 & 13,648 & 15,150 & 17,044 \\
\hline Shaanxi & 1,339 & 1,691 & 2,051 & 4,006 & 3,728 & 3,691 & 6,608 & 4,793 & 5,321 & 6,617 & 7,322 & 8,127 & 9,143 \\
\hline Gansu & 666 & 900 & 600 & 2,318 & 1,029 & 1,052 & 2,817 & 1,803 & 2,270 & 2,493 & 2,759 & 3,093 & 3,479 \\
\hline Qinghai & 116 & & & & & & & & & & 472 & & 596 \\
\hline Ningxia & 212 & 243 & 261 & 338 & 443 & 536 & & 702 & 865 & 983 & 1,094 & 1,218 & 1,356 \\
\hline Xinjiang & 588 & 949 & 713 & 874 & 907 & 1,167 & 3,589 & 3,141 & 2,259 & 2,713 & 3,009 & 3,337 & 3,754 \\
\hline
\end{tabular}

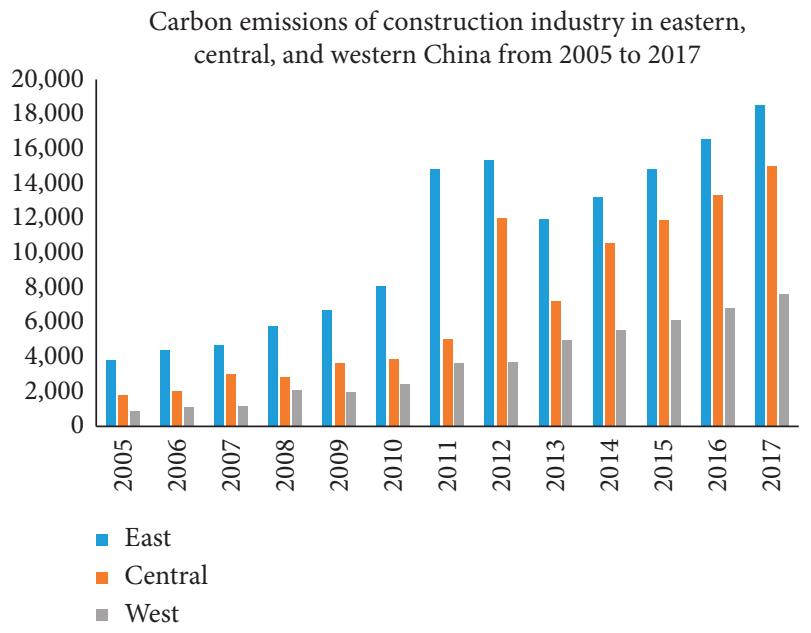

FIgURE 1: Carbon emissions of construction industry in eastern, central, and western China from 2005 to 2017.

Considering the low carbonization degree of industry and energy comprehensively, the low carbonization evaluation equation of related industries is obtained as follows:

$$
\mathrm{XGCY}=\mathrm{GYDT} \times \omega_{3}+\mathrm{NYDT} \times \omega_{4},
$$

where GYDT is the low-carbon degree of industry, NYDT is the low-carbon degree of energy, XGCY is the low carbon in related industries, $\omega_{3}$ and $\omega_{4}$ are the weight coefficients obtained by the entropy weight method, and $\omega_{3}+\omega_{4}=1$.

(4) The low-carbon level of the construction industry is reflected in the two indicators: the energy consumption of the construction industry and the energy consumption of the construction industry in the region. The smaller the energy consumption of the construction industry, the higher the low-carbon level and the smaller the proportion of energy consumption. This shows that the higher the low carbonation level, the two indicators have a linkage effect. Thus, the equation for establishing a low carbonization level in the construction industry is as follows:

$$
\mathrm{JZTP}=\mathrm{NYB} \times \omega_{5}+\mathrm{NNXH} \omega_{6},
$$

where NYB is the energy consumption proportion of the construction industry, $\mathrm{NNXH}$ is the total energy consumption in the construction industry, JZTP is the structure of low carbon in the construction industry, $\omega_{5}$ and $\omega_{6}$ are the weight coefficients obtained by the entropy weight method, and $\omega_{5}+\omega_{6}=1$. 


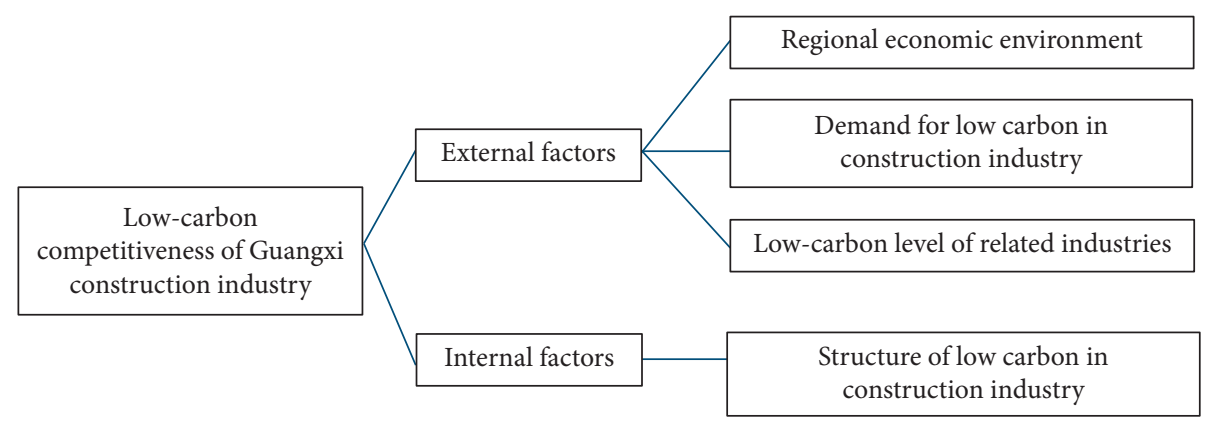

FIgURE 2: Structure of influencing factors on the low-carbon competitiveness of the Guangxi construction industry.
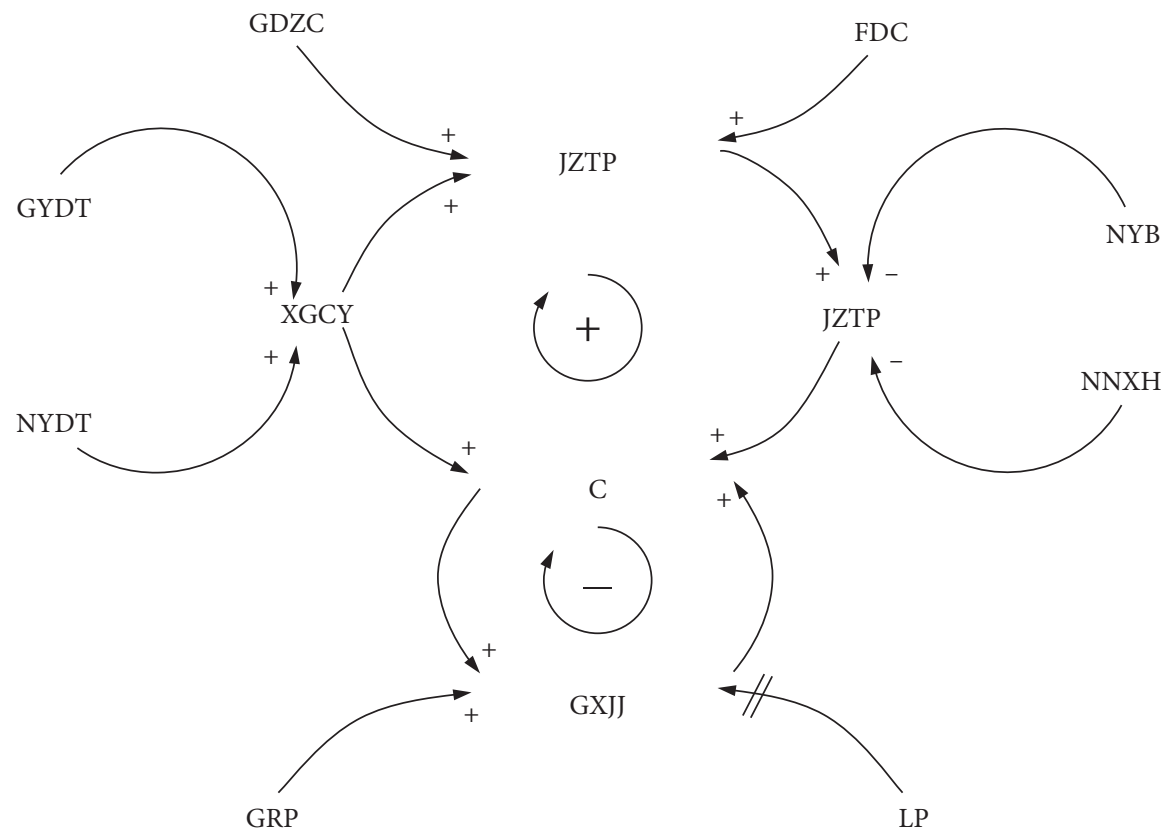

FIgURe 3: Causal flow diagram of the influencing factors of low-carbon competitiveness in the Guangxi construction industry.

(5) Low-carbon competitiveness equation of the Guangxi construction industry: in accordance with the causal flow and the aforementioned equation, the low-carbon competitiveness equation of the Guangxi construction industry is affected by the Guangxi regional economic environment (GXJJ), low-carbon demand of construction products (JZCP), low-carbon of related industries (XGCY), and carbon emission of the construction industry (JZTP). Using the aforementioned variables, the low-carbon competitiveness equation of the Guangxi construction industry is established as follows:

$C=\mathrm{GXJJ} \times \omega_{7}+\mathrm{JZCP} \omega_{8}+\mathrm{XGCY} \omega_{9}+\operatorname{JZTP} \omega_{10}$,

where $\omega_{7}, \omega_{8}, \omega_{9}, \omega_{10}$ are the weight coefficients obtained by the entropy weight method, and $\omega_{7}+\omega_{8}+\omega_{9}+\omega_{10}=1$.
According to the establishment of the aforementioned equation and system dynamics, the model in Figure 4 is established for the data trial and empirical simulation.

\subsection{Establishment of a Low-Carbon Competitiveness Model for the Construction Industry in Guangxi}

2.4.1. Determination of Influence Coefficient. The relevant economic indicators of the Guangxi construction industry are shown in Table 3.

According to the curve of Guangxi regional GDP and Guangxi construction industry GDP, we determine $f(y)$ in Figure 5.

$f(y)=7072 \ln (x)-39785$ can be obtained through a curve fitting calculation and $R^{2}=0.9861$ indicates that the fitting degree is good; now, equation (3) can be further defined as follows:

$$
\mathrm{GXJJ}=[1+7072 \ln (x)-39875] \times \mathrm{GRP} \times\left\{\left[7072 \ln \left[2-(1.5)^{a}\right]-39875\right\}\right.
$$




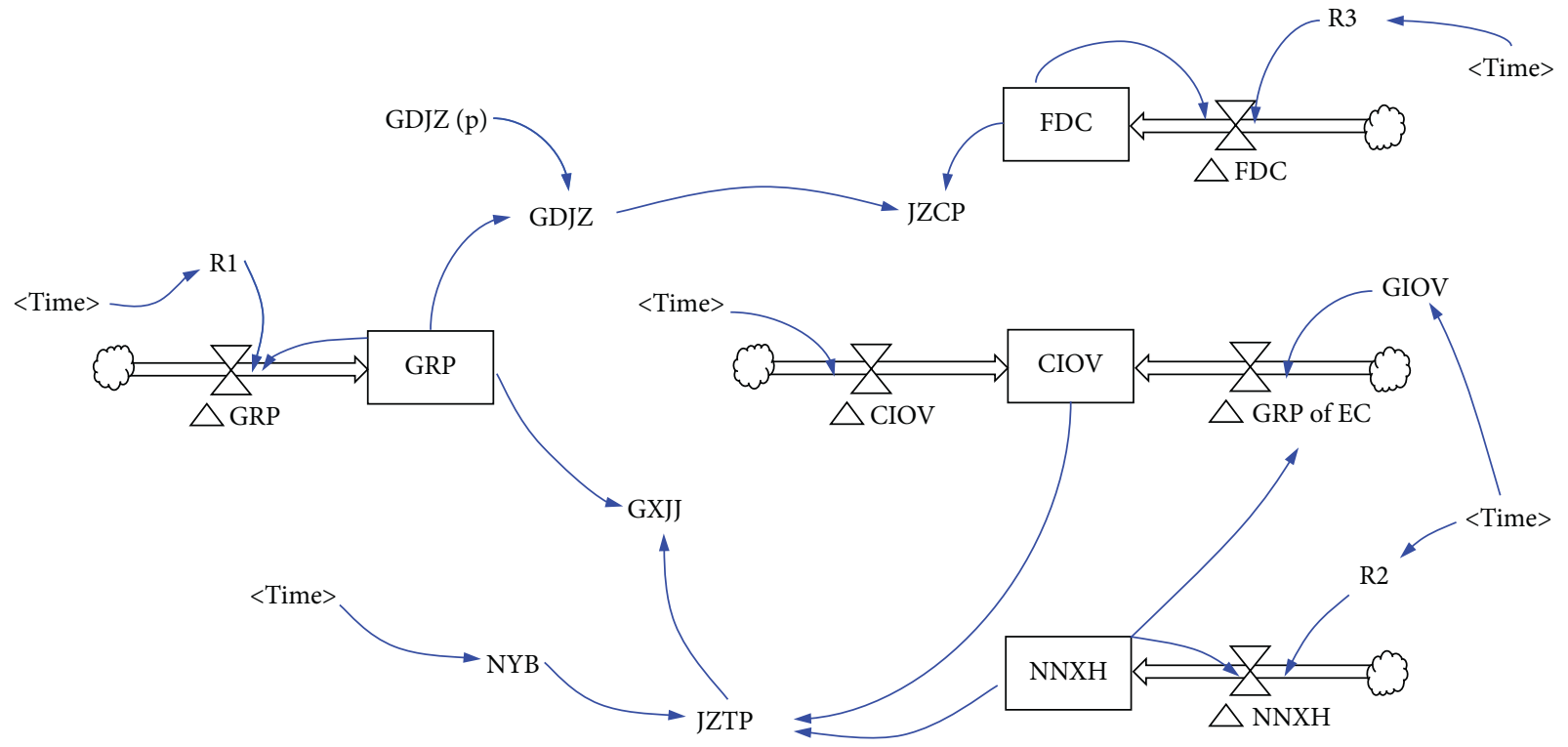

FIGURE 4: System dynamics model of the Guangxi construction industry low-carbon competitiveness.

TABLE 3: Relevant economic indicators of the Guangxi construction industry.

\begin{tabular}{|c|c|c|c|c|c|c|c|c|}
\hline Year & $\begin{array}{l}\text { Gross } \\
\text { regional } \\
\text { product } \\
\text { (GRP) } \\
\text { (billion } \\
\text { yuan) }\end{array}$ & $\begin{array}{c}\text { Guangxi } \\
\text { construction } \\
\text { industry } \\
\text { output value } \\
\text { (billion yuan) }\end{array}$ & $\begin{array}{c}\text { Fixed asset } \\
\text { investment } \\
(100 \text { million } \\
\text { yuan })\end{array}$ & $\begin{array}{l}\text { Real estate } \\
\text { investment } \\
\text { completed } \\
\text { (100 million } \\
\text { yuan) }\end{array}$ & $\begin{array}{l}\text { Gross industrial } \\
\text { output value } \\
\text { per ton of } \\
\text { energy } \\
\text { consumption } \\
\text { (yuan) }\end{array}$ & $\begin{array}{l}\text { Gross regional } \\
\text { production per } \\
\text { ton of energy } \\
\text { consumption } \\
\text { (yuan) }\end{array}$ & $\begin{array}{l}\text { Total energy } \\
\text { consumption of } \\
\text { the construction } \\
\text { industry }(10,000 \\
\text { tons of standard } \\
\text { coal) }\end{array}$ & $\begin{array}{l}\text { Structure of low- } \\
\text { carbon in the } \\
\text { construction } \\
\text { industry (energy } \\
\text { consumption } \\
\text { proportion of the } \\
\text { construction } \\
\text { industry) }\end{array}$ \\
\hline 2005 & 3984.10 & 425.21 & 900.87 & 286.79 & $10,273.00$ & 8182.00 & 33.12 & 0.70 \\
\hline 2006 & 4746.16 & 512.83 & 1170.65 & 369.98 & $12,081.00$ & 9449.00 & 49.13 & 0.89 \\
\hline 2007 & 5835.33 & 612.74 & 1438.54 & 536.28 & $13,843.00$ & $10,420.00$ & 44.46 & 0.72 \\
\hline 2008 & 7021.00 & 753.21 & 1805.77 & 627.34 & $15,983.00$ & $11,597.00$ & 41.45 & 0.62 \\
\hline 2009 & 7759.16 & 934.38 & 2614.53 & 813.68 & $16,678.00$ & $11,769.00$ & 35.90 & 0.54 \\
\hline 2010 & 9569.85 & 1222.31 & 3479.48 & 1206.22 & $21,277.00$ & $12,969.00$ & 37.14 & 0.47 \\
\hline 2011 & $11,720.87$ & 1553.07 & 4185.39 & 1517.47 & $24,235.00$ & $14,640.00$ & 40.83 & 0.50 \\
\hline 2012 & $13,035.10$ & 1867.06 & 4975.44 & 1554.94 & $26,144.00$ & $15,280.00$ & 42.65 & 0.50 \\
\hline 2013 & $14,449.90$ & 2289.88 & 4501.24 & 1614.63 & $26,489.00$ & $15,799.00$ & 46.67 & 0.50 \\
\hline 2014 & $15,672.89$ & 2608.91 & 5418.23 & 1838.49 & $31,467.00$ & $16,156.00$ & 50.54 & 0.50 \\
\hline 2015 & $16,803.12$ & 2953.42 & 6680.15 & 1909.09 & $34,062.00$ & $17,215.00$ & 59.90 & 0.60 \\
\hline 2016 & $18,317.64$ & 3434.33 & 8141.87 & 2397.99 & $33,439.00$ & $18,078.00$ & 62.06 & 0.60 \\
\hline 2017 & $20,369.25$ & 4209.72 & $11,438.26$ & 2683.48 & $38,540.00$ & $19,502.00$ & 69.00 & 0.70 \\
\hline
\end{tabular}

Note: data are from the Guangxi Statistical Yearbook (2006-2018).

$X_{1}=f\left(x_{1}\right)=0.06 x^{1.4354}$ can be obtained through a curve fitting calculation, and $R^{2}=0.977$ indicates that the fitting degree is good. $X_{2}=f\left(x_{2}\right)=0.0048 x^{1.3363}$ and $R^{2}=$ 0.9874 indicate that the fitting degree is good, as shown in Figure 6.

2.4.2. Entropy Weight Method to Determine Weight. The entropy weight method is adopted to determine the weight of each index, and the following steps are adopted [45, 46]:

(1) Data Standardization. In accordance with the table of 2005-2017, in these 13 years of multiple indicators for standardization, the standardization formula is $Y_{i j}=x_{i j}-\min \left(X_{i}\right) / \max \left(X_{i}\right)-\min \left(X_{i}\right)$.

(2) Seek Information Entropy. According to the definition of information entropy, we find the information entropy of each group of data, $E_{j}=-\ln (1 / n) \sum_{i=1}^{n} p_{i j} \ln p_{i j}$, where $\quad p_{i j}=$ $Y_{i j} / \sum_{i=1}^{n} Y_{i j}$ if $p_{i j}=0$. We define that $\lim _{p_{i j} \longrightarrow 0} p_{i j} \ln p_{i j}=0$

(3) Determine Index Weight. After the information entropy is obtained, the weight of each index is obtained through the formula $W_{i}=$ $1-E_{i} / k-\sum E_{i}(i=1,2, \ldots, k)$. 


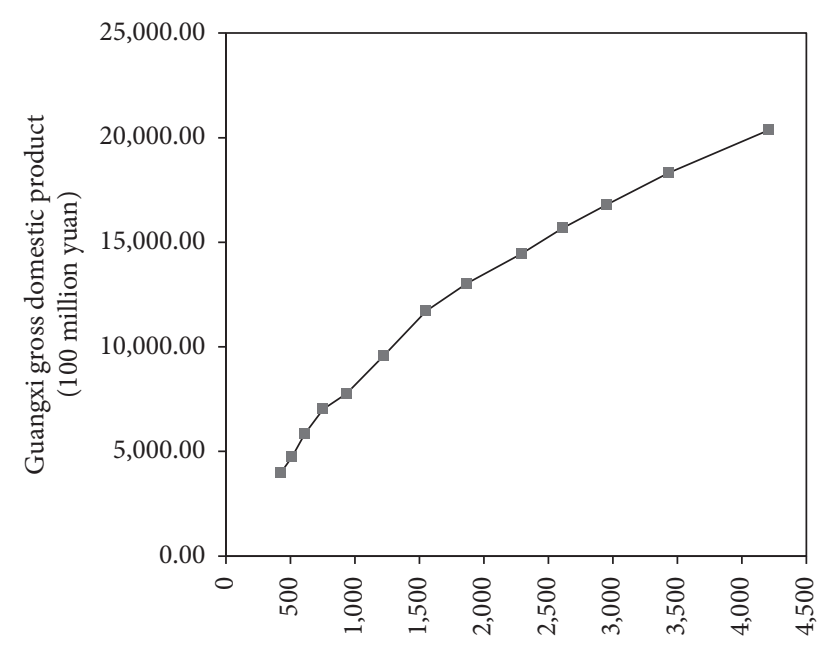

Gross out value of construction enterprises (100 million yuan)

FIgURE 5: Curve of GRP and Guangxi construction industry GDP.

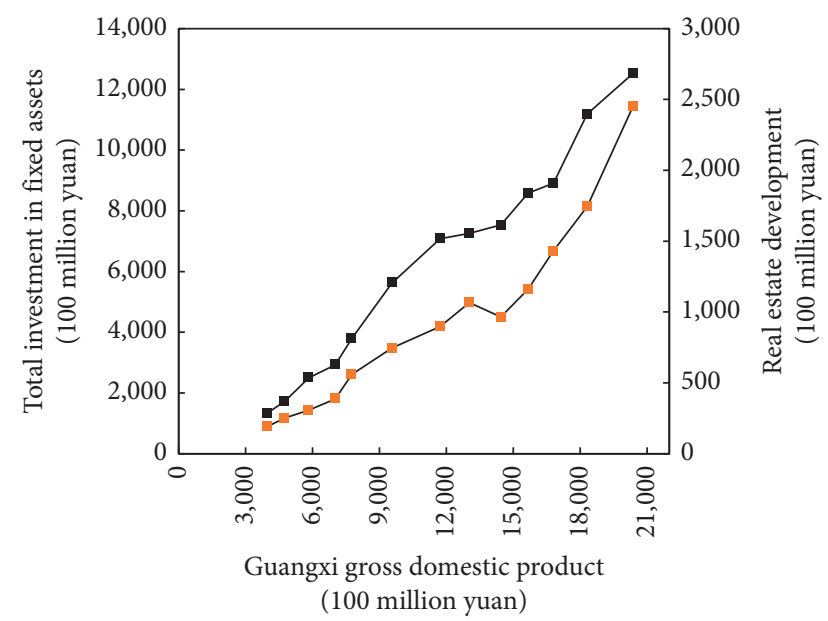

FIgURE 6: Fitting curve of Guangxi GDP, completed real estate investment, and fixed asset investment.

After data standardization, we obtain the data in Table 4.

Thus, the information entropy of each index can be obtained in Table 5 .

\section{Discussion}

3.1. Parameter Selection. In addition to the weight coefficient calculated based on the relevant data of Guangxi from 2005 to 2017, the time interval for the simulation of the model should be determined before the simulation is conducted. The simulation time interval we use is from 2010 to $2020-10$ years. The simulation interval covers most of the original data selection interval, fully reflects the influence of the original data on the model, facilitates the observation and analysis of the data, and is in line with Guangxi's "Twelfth Five-Year Plan" "Study Report" and the "Guangxi Circular Economy Development" Thirteenth Five-Year Plan "Research Report," which have proposed the development period of the circular economy. The implementation of the policy has been evaluated and predicted.

In the choice of simulation step size, generally, the minimum time length of the model is $0.1-0.5$. The minimum time constant of the model is the reciprocal of the minimum constant in the model. To ensure that the simulation step size must be less than the length of the firstorder delay in the model, notably, the smaller the step size, the higher the simulation accuracy. Therefore, after we consider the data characteristics, the step size of this simulation is determined as one year according to the data time, which is more in line with the simulation and actual needs.

The verification of the model is automatically adjusted by VENSIM PLE software. After the data and functions are added, it can be conducted smoothly, demonstrating that the established simulation model is feasible.

\subsection{Analysis of Simulation Results}

3.2.1. Guangxi Region Economic Parameter Adjustment and Result Analysis. By adjusting the proportion of fixed assets in the low-carbon product demand evaluation equation of the construction industry, we can observe changes in the low-carbon level curve of the construction industry in Guangxi (Figure 7).

In accordance with the data in Figure 6, the proportion of fixed asset investment is initially set at $39.5 \%$. By increasing the proportion of fixed asset investment to $40 \%$, the low-carbon level of the Guangxi construction industry also increases, and the increase is gradual from 2010 to 2020. This finding shows that the increase in the fixed asset investment proportion has a pulling effect on the lowcarbon level of the Guangxi construction industry and increases with time in the forecast interval; the pull effect is significant.

3.2.2. Parameter Adjustment and Result Analysis of the Guangxi Construction Industry. In the model, the impact coefficient of real estate investment completion was originally set as 0.425 ; now, we increase it to 0.5 . The low-carbon level curve of the Guangxi construction industry is presented in Figure 8.

We observe that the impact coefficient of real estate investment completion is positively related to the lowcarbon level of the Guangxi construction industry; it is positively related to the value. Therefore, the impact coefficient can be improved by increasing the proportion of real estate investment completion, ultimately promoting the low-carbon level of the Guangxi construction industry.

3.2.3. Energy Parameter Adjustment and Result Analysis of the Guangxi Construction Industry. By raising the overall rate of change of energy consumption in the construction industry by $5 \%$, a comparative chart of the trend of low carbonization in the construction industry can be obtained. 
TABLE 4: Standardized data of the relevant economic indicators of the Guangxi construction industry.

\begin{tabular}{|c|c|c|c|c|c|c|c|}
\hline \multirow[b]{2}{*}{$\begin{array}{l}\omega \\
\text { Year }\end{array}$} & \multirow[b]{2}{*}{$\begin{array}{l}\omega_{7} \\
\text { Gross } \\
\text { regional } \\
\text { product } \\
\text { (GRP) } \\
\text { (billion } \\
\text { yuan) }\end{array}$} & \multicolumn{2}{|c|}{$\omega_{8}$} & \multicolumn{2}{|c|}{$\omega_{9}$} & \multicolumn{2}{|r|}{$\omega_{10}$} \\
\hline & & $\begin{array}{c}\text { Fixed assets } \\
\text { investment } \\
\text { (100 million } \\
\text { yuan) }\end{array}$ & $\begin{array}{c}\text { Real estate } \\
\text { investment } \\
\text { completed (100 } \\
\text { million yuan) }\end{array}$ & $\begin{array}{l}\text { Gross industrial } \\
\text { output value per } \\
\text { ton of energy } \\
\text { consumption } \\
\text { (yuan) }\end{array}$ & $\begin{array}{l}\text { Gross regional } \\
\text { production per } \\
\text { ton of energy } \\
\text { consumption } \\
\text { (yuan) }\end{array}$ & $\begin{array}{c}\omega_{5} \\
\text { Total energy } \\
\text { consumption of the } \\
\text { construction } \\
\text { industry }(10,000 \\
\text { tons of standard } \\
\text { coal) }\end{array}$ & $\begin{array}{c}\omega_{6} \\
\text { Structure of low } \\
\text { carbon in the } \\
\text { construction industry } \\
\text { (energy consumption } \\
\text { proportion of the } \\
\text { construction } \\
\text { industry) }\end{array}$ \\
\hline 2005 & 0.00 & 0.00 & 0.00 & 0.00 & 0.00 & 0.00 & 0.55 \\
\hline 2006 & 0.05 & 0.03 & 0.03 & 0.06 & 0.11 & 0.45 & 1.00 \\
\hline 2007 & 0.11 & 0.05 & 0.10 & 0.13 & 0.20 & 0.32 & 0.60 \\
\hline 2008 & 0.19 & 0.09 & 0.14 & 0.20 & 0.30 & 0.23 & 0.36 \\
\hline 2009 & 0.23 & 0.16 & 0.22 & 0.23 & 0.32 & 0.08 & 0.17 \\
\hline 2010 & 0.34 & 0.24 & 0.38 & 0.39 & 0.42 & 0.11 & 0.00 \\
\hline 2011 & 0.47 & 0.31 & 0.51 & 0.49 & 0.57 & 0.21 & 0.07 \\
\hline 2012 & 0.55 & 0.39 & 0.53 & 0.56 & 0.63 & 0.27 & 0.07 \\
\hline 2013 & 0.64 & 0.34 & 0.55 & 0.57 & 0.67 & 0.38 & 0.07 \\
\hline 2014 & 0.71 & 0.43 & 0.65 & 0.75 & 0.70 & 0.49 & 0.07 \\
\hline 2015 & 0.78 & 0.55 & 0.68 & 0.84 & 0.80 & 0.75 & 0.31 \\
\hline 2016 & 0.87 & 0.69 & 0.88 & 0.82 & 0.87 & 0.81 & 0.31 \\
\hline 2017 & 1.00 & 1.00 & 1.00 & 1.00 & 1.00 & 1.00 & 0.55 \\
\hline
\end{tabular}

TABLE 5: Information entropy and entropy weight of each index.

\begin{tabular}{cccccccccrc}
\hline & $\omega_{1}$ & $\omega_{2}$ & $\omega_{3}$ & $\omega_{4}$ & $\omega_{5}$ & $\omega_{6}$ & $\omega_{7}$ & $\omega_{8}$ & $\omega_{9}$ & $\omega_{10}$ \\
\hline$E_{j}$ & 0.85 & 0.88 & 0.89 & 0.92 & 0.89 & 0.85 & 0.89 & 0.86 & 0.90 & 0.88 \\
& $\omega_{1}+\omega_{2}=1$ & $\omega_{3}+\omega_{4}=1$ & $\omega_{5}+\omega_{6}=1$ & & $\omega_{7}+\omega_{8}+\omega_{9}+\omega_{10}=1$ & 0.30 & 0.21 & 0.25 \\
$\omega_{j}$ & 0.56 & 0.44 & 0.56 & 0.44 & 0.42 & 0.58 & 0.24 & 0.30 \\
\hline
\end{tabular}

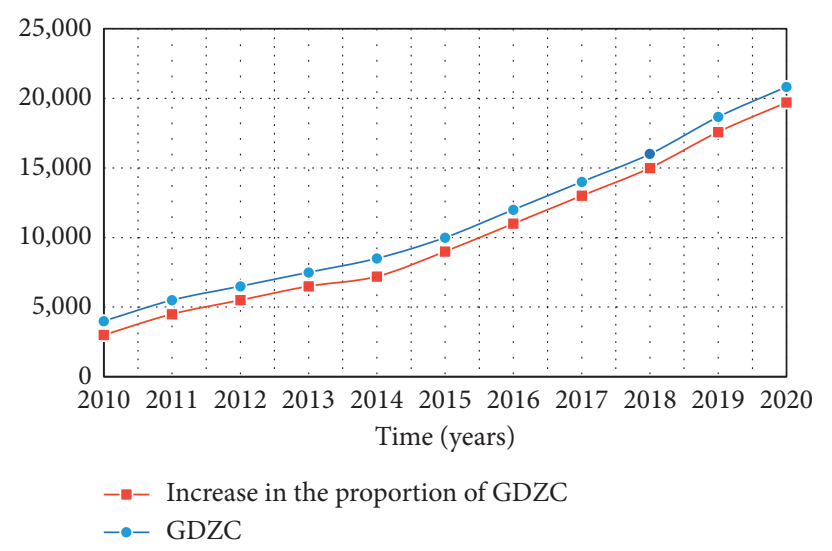

Figure 7: Influence of economic parameter adjustment on the low-carbon level of the construction industry in Guangxi.

In Figure 9, the increase in energy consumption in the construction industry directly leads to an increase in the low-carbon index of the construction industry. However, in the simulated time interval, the energy consumption level curve of the construction industry before 2014 and the low-carbon level curve of the Guangxi construction industry are highly fitted, which conforms to the relevant data of the Guangxi construction industry. From 2014 to 2020, there is a significant pulling effect, and the increment increases annually. 


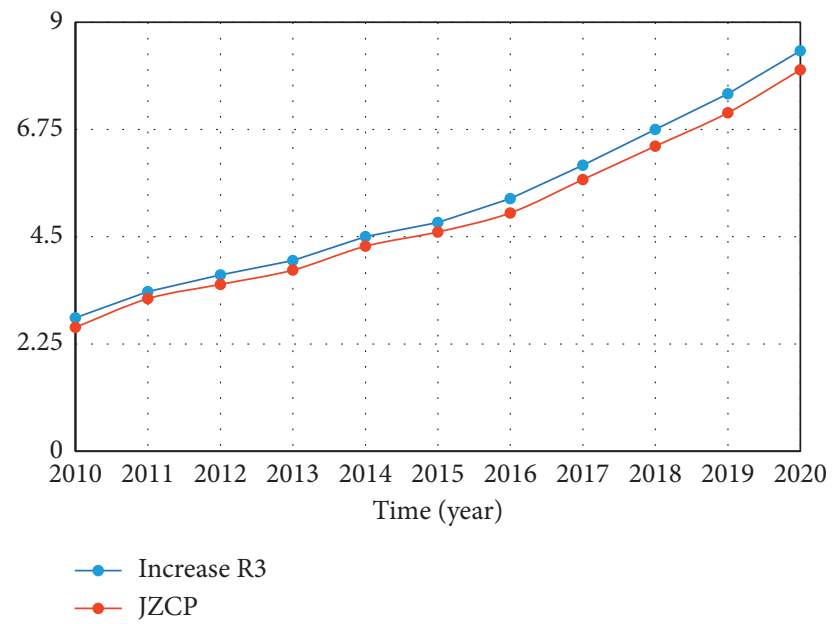

Figure 8: Impact of the adjustment of relevant construction parameters on the low-carbon level of the construction industry in Guangxi.

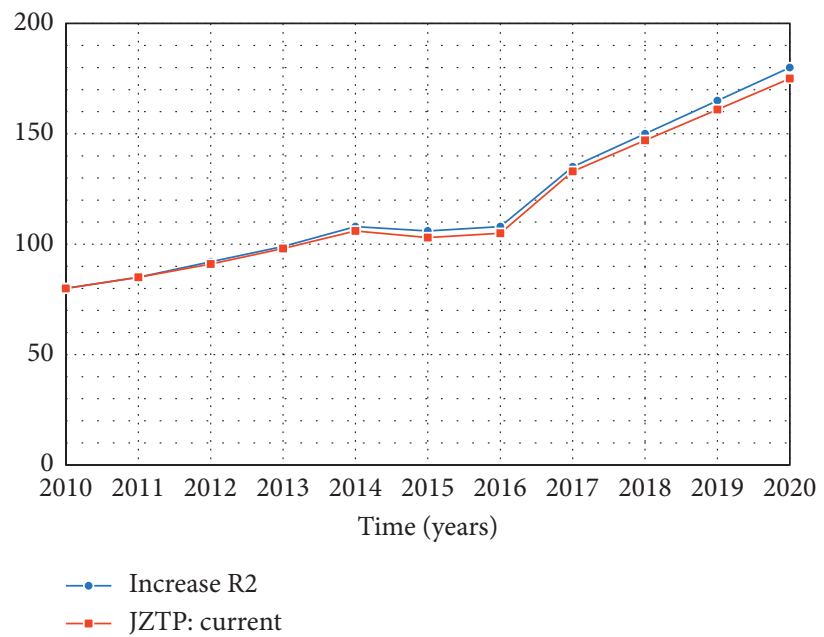

FIGURE 9: Impact of energy parameter adjustment on low-carbon level of the construction industry in Guangxi.

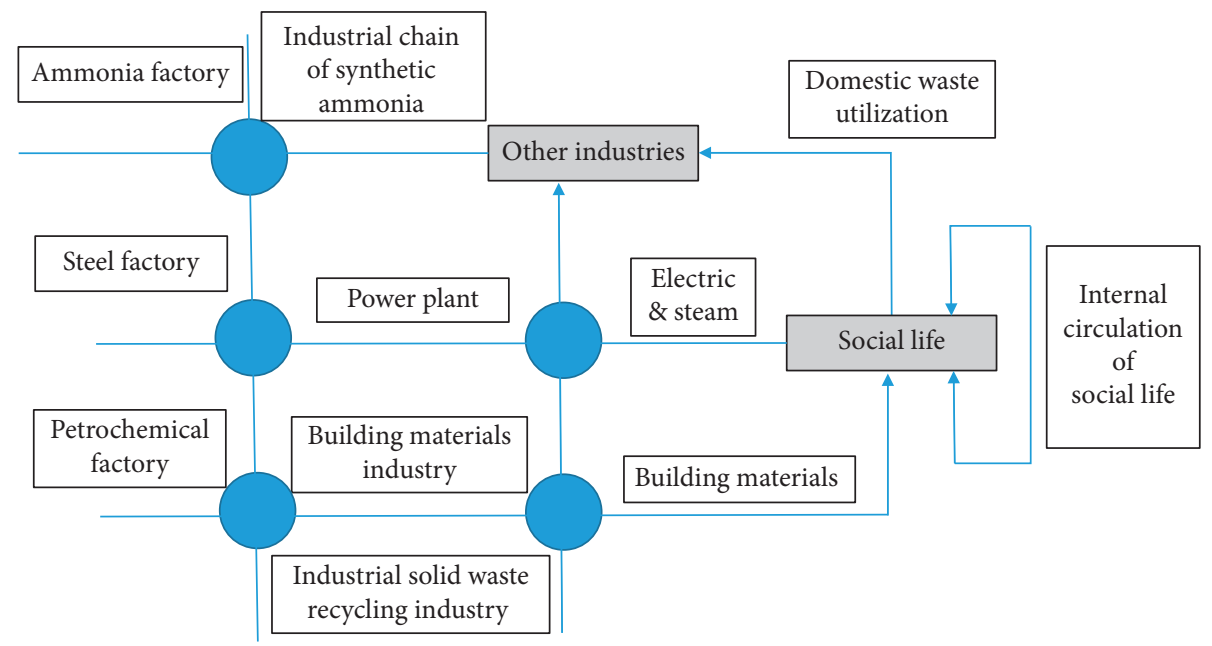

FIGURE 10: Modern circular economy with multi-industry integration related to the construction industry. 


\section{Conclusions and Recommendations}

4.1. Conclusions. By deconstructing the low-carbon factors of Guangxi's construction industry from the perspective of the circular economy, first, a causal flow analysis of the impact of many factors on the low-carbon construction industry in Guangxi was conducted. Based on the causal flow analysis, the combination of factors that have a critical impact on the low-carbon construction industry in Guangxi was proposed in the context of system dynamics to build a system dynamics model, adopt the relevant economic and energy indicators of the construction industry in Guangxi from 2005 to 2017, determine the coefficients of the model through regression simulation and the information entropy method, and define 2010-2020 as the observation interval to conduct the simulations to evaluate and predict the relevant achievements of Guangxi's circular economy.

According to the running results of the simulation model, we propose the following conclusions:

(1) The regional economic level, development level of the construction industry, and industrial energy consumption level of the construction industry will have a significant impact on the low-carbon level of Guangxi's construction industry, and the effect is regional economic level $>$ development level of the construction industry > energy consumption level of the construction industry.

(2) Regional economic environment has a significant pulling effect on the low-carbon level of the construction industry. The pulling effect of the regional economic environment is mainly reflected in the setting of the initial value of the regional economy, which means that the better the foundation of the regional economic environment, the lower the carbon level. The promotion effect is more obvious, but because the model in this paper is based on the Guangxi region as a geographic category for research, and the regional economic level is a known parameter value, it can only focus on the improvement of the regional economic environment in the process of developing a low-carbon economy in the construction industry in the later period. We suggest the following: increase the proportion of the regional economy and fixed asset investment to increase GDP and GDP per capita to drive the low-carbon level of the construction industry in the region.

(3) From the model of factors influencing the competitiveness of the construction industry in Guangxi from 2010 to 2020, we observe that the energy consumption level of the relevant construction industry has a significant impact on the low-carbon competitiveness of the construction industry in this region and has a stimulating effect. The energy consumption level is not high in the horizontal comparison of 31 provinces and cities in the country, has a limited impact on the low-carbon level of the construction industry, and is not as significant as the regional economy in the multifactor comparison.
4.2. Suggestions. In accordance with the current industrial development characteristics of Guangxi and the aforementioned analysis of the low-carbon competitiveness of the construction industry, to achieve the objectives and requirements of the circular economy proposed in the 13th Five-Year Plan Research Report of circular economy development in Guangxi, the regional circular economy can be developed by realizing the following aspects.

\subsubsection{Multi-Industry Integration in a Modern Circular} Economy. This term is not limited to a specific industry and integrates various industries to achieve cross-industry cooperation. Through the production process or production technology, multi-industry enterprises are organically combined, and the waste from the production process of the previous industry is used as the raw material of the downstream industry. Through the idea of "reuse" in the circular economy, by relying on the upgrading of modern industrial technology, production is optimized and improved. Link, improve the efficiency of resource utilization, open the production and circulation channels of various industries, and realize integrated optimization. On the one hand, it reduces the discharge of waste and improves the utilization rate of resources; on the other hand, it protects the environment, realizes sustainable development, and improves economic benefits. The circulation path is shown in Figure 10.

\subsubsection{Building a Circular Economy Demonstration Project} Based on Cities. Based on the characteristics and reality of the development of industries in Guangxi's cities, the city's resource reserves and the current situation of the development of various industries are fully considered, and the advantages and disadvantages are avoided. The city is used as a driver of the whole region to form a "point-line-surface" circular economy linkage mode; optimize the allocation of resources in each city; formulate corresponding policies and plans for each city; and promote the sound, rapid development of the circular economy in the whole region by rapidly improving the development level of the circular economy in the city by, for example, "building a nest and attracting a phoenix city circular economy project," "industrial chain network weaving and spreading a city circular economy project," and "leading industry pulling city circular economy project" (The 18th National Congress of China, 2020).

\subsubsection{Focusing on the Key Technology of a Circular Economy} in the Construction Industry. Within the scope of the construction industry, attention should be paid to the improvement of various industrial technologies, for example, technologies and standards for improving the thermal insulation, waterproofing, and thermal insulation performance of building envelopes in architectural design standards. In the process of building equipment, the system efficiency of air conditioning, lighting, elevators, and hot water should be fully used to reduce losses and improve the 
technical level and equipment performance. In terms of building energy conservation, large-scale use of renewable resources (e.g., solar energy and wind energy) is recommended. Finally, we suggest promoting the application of new building materials and building material production methods through technological reforms and industrial transformation and upgrading.

\section{Abbreviation}

GXJZ: Low-carbon competitiveness of the Guangxi construction industry

GXJJ: Regional economic environment of Guangxi

JZCP: Demand for low carbon in construction products

XGCY: Low-carbon level of related industries

JZTP: Structure of low carbon in the construction industry

GRP: Gross regional products

GDZC: $\quad$ Fixed asset investment of Guangxi

GDZC(p): Proportion of fixed assets investment of Guangxi

FDC: $\quad$ Real estate investment of Guangxi

$\triangle F D C$ : Added to real estate investment of Guangxi

GYDT: Low-carbon degree of industry

NYDT: Low-carbon degree of energy

NYB: $\quad$ Energy consumption proportion of the construction industry

NNXH: Energy consumption of the construction industry in Guangxi

$\triangle \mathrm{NNXH}$ : Added to the energy consumption of the construction industry in Guangxi

CIOV: Construction industry output value

$\triangle \mathrm{CIOV}$ : Added to the construction industry output value

EC: $\quad$ Energy consumption

R1: $\quad$ Rate of change in GRP

R2: $\quad$ Rate of change in EC

R3: $\quad$ Rate of change in FDC

LP: $\quad$ Local protection.

\section{Data Availability}

Publicly available datasets were analyzed in this study. These data can be found in China Statistical Yearbook (http:// www.stats.gov.cn/english/) and Guangxi Statistical Yearbook (http://tjj.gxzf.gov.cn/tjsj/tjnj/).

\section{Conflicts of Interest}

The authors declare that they have no conflicts of interest.

\section{Authors' Contributions}

All the authors contributed to the study conception and design. Material preparation, data collection, and analysis were performed by XL and FL. The first draft of the manuscript was written by XL, and all authors commented on the previous versions of the manuscript. All the authors read and approved the final manuscript.

\section{Acknowledgments}

The authors acknowledge the financial support from the National Natural Science Foundation of China-Study on the dynamic mechanism and policy of Cultural Industry agglomeration in the Tibetan-qiang-yi corridor based on the economic geography (71974155), Key Industry Innovation Chain (group)-Social Development Fund project of Shaanxi Provincial Science and Technology Department: Construction and Demonstration of Green Eco-Industrial Chain in Han River Economic Zone (2019ZDLSF06-07), and the Basic Competence Improvement Project for Middle and Young Teachers in the Universities and Colleges of Guangxi-Application and Practice of BIM in Informatization Treatment of Quality Control in Assembly Construction (Grant no. 2018KY1010).

\section{References}

[1] The 18th National Congress of the Communist Party of China, China Economic Net, 2020, http://news.cnwest.com/ node_38846.htmm.

[2] "State Council General Office's views on promoting the sustainable and healthy development of the construction industry," Architectural Engineering and Design Management, vol. 34, pp. 26-28, 2017.

[3] J. Heping, "Study on the construction path of circular economy in Guangxi industrial park," Academic Forum, vol. 38, 2015.

[4] W. Fangning, Q. Lin, H. Shucheng, and Y. Ruigang, "Problems and countermeasures of the development of circular economy in Guangxi," South China Agricultural, vol. 13, no. $13,2019$.

[5] L. Huajia, "Study on the development of circular economy in Guangxi," Dissertation, Dissertation2011.

[6] X. Xiong and Y. Tang, "Strategic development of Beibu Gulf economic zone of Guangxi: from the perspective of low carbon economy," Lecture Notes in Electrical Engineering, vol. 242, pp. 1251-1260, 2014.

[7] Z. Fang, "Research on development pattern of low-carbon economy industrial park in economic zone of Guangxi Beibu Gulf," Open Cybernetics \& Systemics Jour, vol. 9, pp. 28692876, 2015.

[8] A. L. M. Grant, "Surface drag and turbulence over an inhomogeneous land surface," Boundary-Layer Meteorology, vol. 56, pp. 309-337, 1991.

[9] K. Momaya and K. Selby, "International competitiveness of the Canadian construction industry: a comparison with Japan and United States," International Journal of Civil Engineering, vol. 25, pp. 640-652, 1998.

[10] M. Betts and G. Ofori, "Competitive advantage in construction: reply," Construction Management and Economics, vol. 11, pp. 73-74, 1993.

[11] R. Li and R. Jiang, "Moving low-carbon construction industry in Jiangsu province: evidence from decomposition and decoupling models," Sustainability, vol. 9, p. 1013, 2017.

[12] J. Dong, C. Deng, X.-M. Wang, and X. Zhang, "Multilevel index decomposition of energy-related carbon emissions and their decoupling from economic growth in northwest China," Energies, vol. 9, p. 680, 2016.

[13] J. Li, Y. Chen, Z. Li, and X. Huang, "Low-carbon economic development in Central Asia based on LMDI decomposition 
and comparative decoupling analyses," Journal of Arid Land, vol. 11, pp. 513-524, 2019.

[14] Y. Zhao, Y. Kuang, and N. Huang, "Decomposition analysis in decoupling transport output from carbon emissions in Guangdong province, China,” Energies, vol. 9, p. 295, 2016.

[15] Y. X. Jiang, "Low-carbon idea of the construction project management process," Applied Mechanics and Materials, vol. 174, pp. 2836-2839, 2012.

[16] L. Jiahong and D. Wenbin, "A study on low carbon development in four central provinces-a case study of Hubei, Hunan, Henan and Anhui provinces," Special Economic Zone, vol. 9, pp. 64-67, 2015.

[17] D. Qingfeng, "Comparative analysis on performance of carbon emission in provincial regions of China: based on method of Malmquist index," Technological and Economic, vol. 31, 2012.

[18] C. Fei and C. Dajian, "Research on the content, models and strategies of low carbon cities," Urban Planning Forum, vol. 4, pp. 7-13, 2009.

[19] L. Juchun and S. Yao, "Research on the evaluation of low carbon competitiveness based on dominance degree," Ecological Economics, vol. 31, pp. 79-83, 2015.

[20] L. Juchun, X. H. Xiao, and L. Luo, "Analysis on formation mechanism of building industry's low-carbon competitiveness based on structural equation modeling," Technological and Economic, vol. 32, pp. 60-64, 2013.

[21] L. Juchun, L. Luo, and Z. Jianjun, "Evaluation for low-carbon competitiveness of construction industry based on interval number," Technological and Economic, vol. 31, pp. 61-64, 2012.

[22] X. Ying and L. Hui, "Economic benefit analysis of construction industry as a pillar industry from high energy consumption to low carbon development," China Economy, vol. 8, pp. 56-57, 2010.

[23] H. Qinghua, W. Ge, X. Jianxun, F. Long, and C. Zhen, "A scientometric analysis of low-carbon technology innovations in construction industry and its political implications," Science and Technology Management Research, vol. 36, pp. 216-220, 2016.

[24] H. Li, H. Mu, and M. Zhang, "Analysis of China's energy consumption impact factors," Procedia Environmental Sciences, vol. 11, pp. 824-830, 2011.

[25] Y. Hao, L. Wang, and C. Lee, "Financial development, energy consumption and China's economic growth: new evidence from provincial panel data," International Review of Economics \& Finance, vol. 69, pp. 1132-1151, 2018

[26] S. Wang, C. Zhou, G. Li, and K. Feng, " $\mathrm{CO}_{2}$, economic growth, and energy consumption in China's provinces: investigating the spatiotemporal and econometric characteristics of China's $\mathrm{CO}_{2}$ emissions," Ecological Indicators, vol. 69, pp. 184-195, 2016.

[27] Y. Nan and Y. Gao, "Statistical and econometric analysis of the impact of China's energy, environment on the economic development," Energy Procedia, vol. 5, pp. 2358-2362, 2011.

[28] S. Pokharel, "An econometric analysis of energy consumption in Nepal," Energy Policy, vol. 35, pp. 350-361, 2007.

[29] C. Li, H. Huo, L. Yajie, and H. Wei, "Evaluation of low-carbon city competitiveness and its obstacle indicators analysis in Shandong province," Resources Science, vol. 7, pp. 1474-1481, 2015.

[30] S. E. Puliafito, J. L. Puliafito, and M. C. Grand, "Modeling population dynamics and economic growth as competing species: an application to $\mathrm{CO}_{2}$ global emissions," Ecological Economics, vol. 65, no. 3, pp. 602-615, 2008.
[31] U. Soytas, R. Sari, and B. T. Ewing, "Energy consumption, income, and carbon emissions in the United States," Ecological Economics, vol. 62, no. 3-4, pp. 482-489, 2007.

[32] S. Si, M. Lyu, C.-Y. C. L. Lawell, and S. Chen, "The effects of energy-related policies on energy consumption in China," Energy Economics, vol. 76, pp. 202-227, 2018.

[33] R. Hoekstra and J. M. van den Bergh, "Comparing structural decomposition analysis and index," Energy Economics, vol. 25, pp. 39-64, 2003.

[34] J. Xu, T. Fleiter, W. Eichhammer, and Y. Fan, "Energy consumption and $\mathrm{CO}_{2}$ emissions in China's cement industry: a perspective from LMDI decomposition analysis," Energy Policy, vol. 50, pp. 821-832, 2012.

[35] Y. Jiang, J. Zhang, D. Asante, and Y. Yang, "Dynamic evaluation of low-carbon competitiveness (LCC) based on improved technique for order preference by similarity to an ideal solution (TOPSIS) method: a case study of Chinese steelworks," Journal of Cleaner Production, vol. 217, pp. 484-492, 2019.

[36] N. Hughes and N. Strachan, "Methodological review of UK and international low carbon scenarios," Energy Policy, vol. 38, no. 10, pp. 6056-6065, 2010.

[37] X. Xiong and Y. Tang, "Strategic development of Beibu Gulf economic zone of Guangxi: from the perspective of low carbon economy," Lecture Notes in Electrical Engineering, vol. 242, pp. 1251-1260, 2014.

[38] Y. Zhao, K. Geng, C. H. Chong et al., "How to effectively control energy consumption growth in China's 29 provinces: a paradigm of multi-regional analysis based on Eaalmdi method," Sustainability, vol. 13, no. 3, p. 1093, 2021.

[39] K. A. Akkemik, K. Göksal, and J. Li, "Energy consumption and income in Chinese provinces: heterogeneous panel causality analysis," Applied Energy, vol. 99, pp. 445-454, 2012.

[40] National Development and Reform Commission: 13th FiveYear Plan for Energy Development, 2021, http://www.ndrc. gov.cn/zcfb/zcfbtz/201701/W020170117335278192779.pdf.

[41] https://www.ipcc.ch/sr15/chapter/spm/ IPCC Special Report: Global Warming of $1.5^{\circ} \mathrm{C}, 2021$,.

[42] L. Juchun, Z. Zhen, and H. Xiaoxiao, "Evolution characteristics of carbon emission in China's construction industry and decomposition of influencing factors with LMDI," Construction Economics, vol. 38, pp. 81-88, 2017.

[43] Q. Zhong, J. Zhang, S. Luo et al., "System dynamics scenario analysis of circular economic development in Guangdong Province," Chinese Journal of Eco-Agriculture, vol. 17, no. 4, pp. 800-806, 2009.

[44] X. Zhangdan, "Research on low-carbon development path of industrial industry based on system dynamics," Dissertation, Dissertation 2016.

[45] J. Feng and Z. R. Gong, "Integrated linguistic entropy weight method and multi-objective programming model for supplier selection and order allocation in a circular economy: a case study," Journal of Cleaner Production, vol. 277, 2020.

[46] Y. Duan, H. Mu, N. Li et al., "Research on comprehensive evaluation of low carbon economy development level based on AHP-entropy method: a case study of Dalian," Energy Procedia, vol. 104, pp. 468-474, 2016. 